\title{
Hubungan berat badan lahir dan pemeriksaan ANC dengan stunting pada anak umur 0-59 bulan
}

\author{
Born and weight relationship ANC examination with stunting in \\ children age 0-59 months \\ Hilki Ofan ${ }^{*}$, Lina Fitriani ${ }^{2}$ \\ ${ }^{1,2}$ STIKES Bina Generasi Polewali Mandar, Jl Mr Muh Yamin No 195 Manding, Polewali Mandar, Sulawesi Barat, 91315 , \\ Indonesia \\ 1'hilkiofan1@gmail.com*; ${ }^{2}$ linafitriani@biges.ac.id \\ *corresponding author \\ Tanggal Submisi: 8 September 2021, Tanggal Penerimaan: 3 Oktober 2021
}

\begin{abstract}
Abstrak
Permasalahan anak pendek (stunting) salah satunya masalah gizi yang terhadapi di dunia, khususnya negara miskin serta berkembang. Penelitianya tersebut punya tujuan guna mendapati korelasi berat badan lahir serta pemeriksaanya ANC berdasar stunting di anak usia 0-59bulan. Desain yang dipergunakan metoda Survey analitic berdasar pendekatanya crosssectional. Populasinya keseluruhan anak usia 0-59bulan. Jumlahnya sample sejumlah 66 anak. Hasil penelitianya korelasi berat badan lahir berdasar terjadinya stunting di anak umur 0-59bulan didapat $0,002 \quad(<0,05)$. Sedang hasilnya penelitian pemeriksaanya ANC berdasar berlangsungnya stunting di anak umur 0-59 bulan didapat $0,000(<0,05)$.
\end{abstract}

Kata kunci: anak usia 0-59 bulan; ANC; BBL; stunting

\section{Abstract}

The problem of short children (stunting) is one of the nutritional problems that are faced in the world, especially in poor and developing countries. The aim of this research is to find a correlation between birth weight and ANC examination based on stunting in children aged 0-59 months. The design used is the analytical survey method based on a cross-sectional approach. The entire population is children aged 0-59 months. The number of samples is 66 children. The results of the research were the correlation between birth weight based on the occurrence of stunting in children aged 0-59 months obtained 0.002 (<0.05). Meanwhile, the results of the ANC examination based on the occurrence of stunting in children aged 0-59 months obtained $0.000(<0.05)$.

Keywords: ANC; BBL; children aged 0-59 months; stunting

\section{PENDAHULUAN}

Stunting yakni wujud gangguan pertumbuhan linear yang berlangsung utamanya di anak (2018). Stunting bisa dikatakan salah satunya indiksi status gizi kronis yang menjelaskan keterhambatan pertumbuhan dikarena malnutrisi berjangka panjang(Siringoringo, Syauqy, Panunggal, Purwanti, \& Widyastuti, 
2020). Permasalahan anak pendek (stunting) bisa dikatakan salah satunya masalah gizi yang ditemui di dunia, lebih khusus di negara miskin serta berkembang(Mustika \& Syamsul, 2018). Stunting jadi masalah dikarena berkorelasi berdasar peningkatanya resiko berlangsungnya sakit serta meninggal, perkembanganya otak sub-optimal hingga perkembanganya motorik terlambat serta keterhambatan pertumbuhanya mental(Adhi, 2019). Berdasar data daripada Riskesdas 2013 guna balita pendek serta sangat pendek sejumlah 37,2\% sedang ditahun 2018 mendapati penyusutan jadi 30,8\%. Meskipun balita pendek serta sangat pendek tersebut mendapati penyusutan tapi guna jumlahnya 30,8\% tersebut masihlah sangat terbilang tinggi(Setiawan et al., 2018). Anak balita berumur 0-59bulan mendapati stunting di Provinsi Sulawesi Barat menggapai 37\% ataupun lebih tinggi dibanding angkanya stunting nasional sejumlah 27,5\%. Data stunting Polewali Mandar sejumlah 12,9\%(Yudianti \& Saeni, 2016).

Stunting ataupun pendek yakni kondisional gagalnya tumbuhkembang di balita yang tertandai berdasar angka tinggi badan perumurnya kurang daripada -2 (nilainya z-score)(Hutasoit, Utami, \& Afriyliani, 2020). Berlangsungnya stunting tersebabkan kondisional kekuranganya gizi kronis didalam rentangan waktu lama di mulai semenjak janin didalam kandunganya hingga awal hidupnya anak (1000hari awal kehidupanya)(Hutasoit et al., 2020). Balita yang mendapati stuntingkan punya tingkatan cerdas tidak maksimum, selain daripada itulah anak jua sangatlah rentan atas sakit serta dimasa mendatang bisa berisiko berlangsungnya penurunan tingkatan produktifitasnya(Yadika, Berawi, \& Nasution, 2019). Pada akirnya secara luas stunting bisa memberi hambatan tumbuhkembang ekonomi serta menumbuhkan kemiskinan(Saputri, 2019).

Ibu yang melaksanakan ANC kurang daripada 4kali, maka resikonya 1,15kali mendominasi guna lahiran BBLR(Fatimah, Utama, \& Sastri, 2018). Stunting di katakan sebagaimana pemberi tanda resiko daripada tumbuhkembang anak, serta bisa dikatakan salah satunya penghambatan yang paling utama atas pembentukanya manusia. Stunting yakni kondisional tubuh yang sangatlah pendek, hingga menyakup defisit 2 standart deviasi (SD) dibawah median panjang maupun tinggi badan populasi yang jadi referensinya internasional, serta bisa dikatakan indikasi suksesnya kesejahteraan, pendidikan serta pendapatanya masyarakat(Yadika et al., 2019). efeknya sangatlah luas, termulai daripada dimensi economi, cerdas, mutu, serta dimensi bangsa yang punya efek dimasa mendatang anak(Supariasa \& Purwaningsih, 2019).

Stunting yakni kondisional tinggi badan berdasar usia (TB/U) di anak balita terdapat dibawah -2SD berdasar pengukuranya antropometri. Stunting memberi indikasi permasalahan gizi kronis sebagaimana akibatnya daripada kondisi yang berlangsungnya lama, misal: kemiskinan serta pola asuh maupun pemberianya makanan yang kurang baik daripada semenjak anak terlahirkan yang memberi akibat anak jadi pendek(Najahah et al., n.d.).

Faktor yang menjadikanya sebab berlangsungnya stunting sangatlah banyak. Aspek tersebut di antaranya berat lahir, tingkatan pendidikanya ibu, jenis kelaminya, tinggi badan ibu, pemberianya ASI esklusif serta statusnya ekonomi(Larasati, 2018). 
Antenatal Care (ANC) yang bermutu disesuai standart yang sudah diberi ketentuan atas Pemerintah yakni 2kali didalam trimester I, 2kali trimester II serta 4kali trimester III guna menurunkanya angka sakit serta meninggalnya ibu(Lisnawati, Arsyad, Hafid, \& Zainul, 2019).

Permasalahan status gizi balita di Indonesia punya disparitas diantaranya area/ provinsi. Berdasar besarnya permasalahan stunting, sebuah kawasan dipandang punya permasalahan stunting ringan bilamana prevalensi stunting ada diantara $20-29 \%$, sedang bilamana $30-39 \%$ serta berat bilamana $>40 \%$ (Java \& Tenggara, 2014).

Selain daripada itulah, penyegahan stunting jua terfokuskan di 1.000 Hari Pertama Kehidupan (H P K), yakni di Ibu mengandung, Ibu memberi asi, Anak 0-23bulan. Priode $1.000 \mathrm{H} \mathrm{P} \mathrm{K}$ bisa dikatakan priode yang efektif didalam mempercegah berlangsungnya stunting dikarena bisa dikatakan priode yang memberi ketentuan mutu kehidupanya. Di $1.000 \mathrm{H} \mathrm{P} \mathrm{K}$ anak bisa mendapti masa "Priode Emas" yang mana tumbuhkembangnya anak bisa terjadi cepat. Maka daripada itulah, di priode tersebut cakupanya gizi wajib terpenuhinya termulai daripada 270hari semasa kehamilanya serta 730 hari awal sesudah bayi terlahirkan. tapi, berdasar $\mathrm{W} H \mathrm{O}$ penyegahan berlangsungnya stunting tidaklah hanya termulai disaat $1.000 \mathrm{H} \mathrm{P} \mathrm{K}$, melainkan termulai disaat remaja bersama perbaikanya gizi disaat remaja(Larasati, 2018).

Bayi berdasar berat lahir rendah bisa menyebabkan 8kali lebih besar kematian. Berdasarkan Profil Kesehatan Provinsi Sulbar Tahun 2019 terdapat 1176 bayi mengalami BBLR yang terdiri dari 412 di kab majene, 426 bayi di Kab Polewali Mandar, 68 bayi di Kab Mamasa, 128 bayi di Kab Mamuju serta 153 bayi di Kab Pasangkayu(15 pendahuluan.pdf, n.d.).

Hasil study awal yang telah dilakukan terdapat jumlah stunting pada tahun 2018 adalah 3032 balita pendek dan sangat pendek. 10 orang ibu yang mempunyai bayi stunting di dapatkan informasi bahwa 4 anak mengalami berat badan lahir rendah (BBLR) dan pemeriksaan ANC kurang dari 8 kali selama hamil. Sedangkan data dari wilayah kerja puskesmas anreapi tahun 2018 sebanyak 223 bayi menderita stunting dari 915 bayi.

\section{METODE}

Desain yang dipergunakan yakni metoda Survey analitc berdasar pendekatan penelitian memergunakan pendekatan crosssectional. Populasi atas penelitianya tersebut yakni keseluruhan anak berusia 0-59bulan yang terdapat diwilayah kerja Puskesmas Anreapi yakni sejumlah 203 korespondensi bersama jumlahnya sample 66 anak instrumen yang dipergunakan yakni KMS serta keterangan lahir guna melihat berat badan bayi disaat terlahir. pengumpulanya data dilaksanakan berdasar melakukan wawancara serta melihat KMS dan surat keterangan lahir dari setiap anak umur 0-59 bulan yang mengalami stunting. setelah itu data akan dikumpulkan dan di analisa Analisa data yang dipergunakan yakni penganalisisan univariat \& bivariate serta pengujian statistic yang dipergunakan yakni ChiSquare guna melihat korelasi diantara variable independen serta dependen. 


\section{HASIL DAN PEMBAHASAN}

Penelitianya di Puskesmas Anreapi Kabupaten Polewali Mandar. Berikut data karakteristik didalam penelitianya tersebut:

Tabel 1. Hubungan Berat Badan Lahir dengan kejadian stunting di Wilayah Kerja Puskesmas Anreapi Kab. Polewali Mandar

\begin{tabular}{cccrrr}
\hline & & \multicolumn{2}{c}{ Stunting } & Total & p-Value \\
\cline { 3 - 4 } BBL & Stunting & Normal & & \\
& BBLR & 13 & 4 & 17 & \\
& $\%$ & $19,7 \%$ & $6,1 \%$ & $25,8 \%$ & \\
& BBLN & 15 & 34 & 49 & 0,002 \\
& $\%$ & $22,7 \%$ & $51,5 \%$ & $74,2 \%$ & \\
& & 28 & 38 & 66 & \\
& Total & & & &
\end{tabular}

Berdasar tabel di atas, 17 anak $(25,8 \%)$ yang punya berat lahir rendah maupun BBLR serta 49 anak $(74,2 \%)$ lahir bersama berat badan lahir normal maupun BBLR. Dari 66 anak di Puskesmas Anreapi terdapat 28 anak $(42,4 \%)$ yang mengalami stunting sedang 38 anak $(57,6 \%)$ tumbuh normal.

Tabel 2. Hubungan Jumlah Pemeriksaan ANC dengan kejadian stunting di Wilayah Kerja Puskesmas Anreapi Kab. Polewali Mandar

\begin{tabular}{|c|c|c|c|c|c|}
\hline & & \multicolumn{2}{|c|}{ Stunting } & \multirow[t]{2}{*}{ Total } & \multirow{2}{*}{$\begin{array}{l}\text { p- } \\
\text { Value }\end{array}$} \\
\hline & & Stunting & Normal & & \\
\hline \multirow{4}{*}{$\begin{array}{l}\text { ANC } \\
\text { examination }\end{array}$} & < 4 Kali & 23 & 5 & 28 & \\
\hline & $\%$ & $34,8 \%$ & $7,6 \%$ & $42, \%$ & \\
\hline & $\geq 4$ Kali & 5 & 33 & 38 & ,000 \\
\hline & $\%$ & $7,6 \%$ & $50,0 \%$ & $57, \%$ & \\
\hline Total & & 28 & 38 & 66 & \\
\hline$\%$ & & $42,4 \%$ & $57,6 \%$ & $100, \%$ & \\
\hline
\end{tabular}

Sumber : Hasil Penelitian tahun 2020

Berdasar tabel di atas didapat bahwasanya jumlahnya ibu yang melaksanakan pemeriksaanya A N C <4kali sejumlah 28 ibu $(42,4 \%)$ serta jumlah ibu yang melaksanakan pemeriksaanya A N C >4kali sejumlah 38 ibu (57,6\%). Dari hasil penelitian terhadap 66 ibu di Puskesmas Anreapi terdapat 28 ibu $(42,4 \%)$ yang punya anak stunting serta 38 ibu $(57,6 \%)$ yang punya anak tidak stunting.

Dari hasil penelitian didapatkan 17 anak (25,8\%) yang mengalami BBLR atau BBLR dan 49 anak $(74,2 \%)$ lahir dengan BBLR normal atau BBLR. Dari hasil penelitian terhadap 66 anak di Puskesmas Anreapi terdapat 28 anak $(42,4 \%)$ yang mengalami stunting sedangkan 38 anak $(57,6 \%)$ tumbuh normal. Hasil uji statistik diperoleh nilai 0,002 dimana nilainya lebih rendah daripada nilainya alpha 0,05 punya arti $\mathrm{H}$ a di terima serta $\mathrm{H} 0$ di tolak 
punya artian terdapatnya korelasi diantara berat badan lahir berdasar kejadianya stunting.

Sedang dari hasilnya penelitian didapat jumlah ibu yang melaksanakan pemeriksaanya A N C <4kali sejumlah 28 ibu (42,4\%) serta jumlahnya ibu yang melaksanakan pemeriksaanya A N C >4kali sejumlah $38 \mathrm{ibu}(57,6 \%)$. . Dari hasilnya penelitian atas 66 ibu di Puskesmas Anreapi terdapatkan 28 ibu $(42,4 \%)$ yang punya anak stunting serta $38 \mathrm{ibu}(57,6 \%)$ yang punya anak tidak stunting. Hasilnya pengujian statistic didapat nilainya 0,000 yang mana nilainya lebih rendah daripada nilainya alpha 0,05 punya arti $\mathrm{Ha}$ di terima serta $\mathrm{H} 0$ di tolak punya arti adanya koralasi diantara frekuensi pemeriksaan ANC berdasar kejadianya stunting.

Prevalensi stunting diseluruh dunia ditahun 2010 di perkirakan sejumlah 171 juta anak, kecenderunganya tersebut di perkirakan bisa menggapai 21,8\% (142 juta) ditahun 2020. Kusus di Asia ditahun 1990 (49\%) menyusut jadi $28 \%$ ditahun 2010, di perkirakan tahun 2020 bisa makin mendapati penurunanya. Indonesia menghuni peringkat paling tinggi ke lima stunting serta urutanya ke empat jumlahnya anak bersama wasting(Rahmawati, 2020).

Di penelitianya tersebut balita stunting yakni balita yang punya nilainya z-score guna indek panjang badan/ tinggi badan (PB/TB) berdasar usia <2 SD(Yadika et al., 2019). Statusnya sosial ekonomi yakni kapabilitas keluarga guna pemenuhan kebutuhanya sandang, pangan serta papan anggota keluarga yang diberi nilai berdasar atas garis kemiskinan(Najahah et al., n.d.).

Hasil penelitianya memperlihatkan bahwasanya terdapatkan korelasi diantara Antenatal Care berdasar berlangsungnya stunting berdasar nilainya $p$ value sejumlah $<0,000$ (nilainya $\mathrm{p}<0,05$ ). Penelitianya tersebut searah berdasar penelitianya di Probolinggo atas Nurmasari\& Sumarni tahun 2018 memperlihatkan ibu mengandung yang tidaklah rutin melaksanakan Antenatal Care bisa berisiko $4 \mathrm{x}$ lipat menderita anemia. Ibu yang tidak terartur mengkonsumsi tablet fe punya resiko 3,46x berisiko guna anemia. Sementara ibu bersama anemia sangatlah punya potensi guna melahirkan bayi atas berat badan rendah serta berikutnya punya potensi guna stunting. Pemeriksaanya Antenatal Care diharap sejumlah 8kali. Di trimester awal I serta II sama-sama $2 \mathrm{kali}$, serta $4 \mathrm{kali}$ di trimester terakir (trimester III). Pemeriksaanya antenatal sangatlah utama, bukan hanya mutunya tapi lebih dikualitasnya kunjungan(Hutasoit et al., 2020).

Stunting dibanding balita berdasar usianya dibawah 1 tahun. Balita usianya 0-23bulan punya resiko rendah atas kejadianya stunting dikarena pelindungan ASI yang didapat. Stunting di balita bisa berrakibat buruk di kehidupan selanjutnya yang sulit dibenahi. Pertumbuhanya fisik punya korelasi berdasar genetik serta aspek selingkungan. Aspek genetik menyakup tinggi badan orangtua. Tinggi badan ibu bisa dikatakan salah satunya aspek resiko berlangsungnya stunting(Larasati, 2018).

\section{SIMPULAN}

Berdasar hasil penelitianya mengenai hubunganya berat badan lahir berdasar berlangsungnya stunting di anak usia 0-59bulan diperoleh nilainya 
$0,002(<0,05)$. Sedang hasilnya penelitian mengenai frekuensi pemeriksaanya ANC berdasar terjadinya stunting di anak usia 0-59bulan didapat nilainya $0,000(<0,05)$. Bisa diberi simpulan bahwasanya adanya korelasi diantara berat badan lahir serta frekuensi pemeriksaanya ANC berdasar kejadianya stunting di anak usia 0-59bulan.

\section{SARAN}

Setiap posyandu bisa melaksanakan refresing kader tentang cara pengukuran dan penimbangan bayi yang benar serta melakukan pengajaran kepada tenaga kesehatan bagaimana menginovasi melaksanakan pendeteksian perempuan KEK sebelum mengandung hingga bisa mendeteksi serta meminimalisirkan keberlangsungan BBLR di bayi disaat lahir, memberi motivasi ibu ikut kelas hamil berdasar basis Whats'Up Group serta Kelas hamil punya basis keluarga. Salah satunya upayanya jua menaikan jumlah kunjungan pemeriksaanya minimum $8 \mathrm{x}$ disaat mengandung dengan jabaran $2 \mathrm{x}$ disaat trimester $1,2 \mathrm{x}$ disaat trimester 2 serta $4 \mathrm{x}$ disaat trimester.

\section{DAFTAR PUSTAKA}

Adhi, K. T. (2019). Gangguan Perkembangan Motorik Dan Kognitif pada Anak Toodler yang Mengalami Stunting di Wilayah Pesisir Surabaya. In Journal of Health Science and Prevention (Vol. 3). https://doi.org/10.29080/jhsp.v3i2.231

Adriani M, Wirjatmadi B.(2014) gizi dan kesehatan balita. Jakarta: Kencana;

Anisa P. (2012) Faktor -Faktor yang Berhubungan dengan Kejadian Stunting pada Balita Usia 25-60 Bulan di Kelurahan Kalibaru Depok. Jakarta: Universitas Indonesia;

Arikunto, S (2010). Prosedur Penelitian Suatu Pendekatan Praktek. : Jakarta Rineka Cipta.

Arikunto (2009). ManajemenPenelitian. Jakarta PT.Rineke Cipta

Cholid Norbuko ( 2009) Metodologi Penelitian. Penerbit : Bumi Aksara. Jakarta

Dinkes Provinsi Sulawesi Barat. 2019. Profil Kesehatan Provinsi Sulawesi Barat 2019.

Fatimah, N., Utama, B. I., \& Sastri, S. (2018). Hubungan Antenatal Care dengan Kejadian Bayi Berat Lahir Rendah pada Ibu Aterm di RSUP Dr. M. Djamil Padang. Jurnal Kesehatan Andalas, 6(3), 615. https://doi.org/10.25077/jka.v6i3.747

Hutasoit, M., Utami, K. D., \& Afriyliani, N. F. (2020). Kunjungan Antenatal Care Berhubungan Dengan Kejadian Stunting. Jurnal Kesehatan Samodra Ilmu, 11(1), 38-47. 
Java, W., \& Tenggara, E. N. (2014). Faktor Risiko Stunting Pada Anak Usia 023 Bulan Di Provinsi Bali, Jawa Barat, Dan Nusa Tenggara Timur. Jurnal Gizi Dan Pangan, 9(2), 125-132. https://doi.org/10.25182/jgp.2014.9.2.\%p

Larasati, N. N. (2018). Faktor-Faktor yang Berhubungan dengan Kejadian Stunting Pada Balita Usia 25-59 bulan di Posyandu Wilayah Puskesmas Wonosari II Tahun 2017. Skripsi, 1-104.

Lisnawati, L.-, Arsyad, G.-, Hafid, F.-, \& Zainul, Z.-. (2019). Penerapan Model Antenatal Care (ANC) Model WHO 2016 Di Kabupaten Poso Dan Parigi Mautong Provinsi Sulawesi Tengah. Jurnal Kesehatan Prima, 13(2), 85. https://doi.org/10.32807/jkp.v13i2.237

Mustika, W., \& Syamsul, D. (2018). Analisis Permasalahan Status Gizi Kurang Pada Balita di Puskesmas Teupah Selatan Kabupaten Simeuleu. Jurnal Kesehatan Global, 1(3), 127. https://doi.org/10.33085/jkg.v1i3.3952

Najahah, I., Adhi, K. T., Pinatih, G. N. I., Najahah, I., Adhi, K. T., \& Pinatih, G. N. I. (n.d.). Laporan hasil penelitian Faktor risiko balita stunting usia 12-36 bulan di Puskesmas Dasan Agung, Mataram, Provinsi Nusa Tenggara Barat Risk factors stunting for 12-36 month old children in Dasan Agung Community Health Centre, Mataram, West Nusa Tengg. 38.

Notoadmodjo. 2010. Metode Penelitian Kesehatan. Jakarta : Rineka Cipta

Rahmawati, L. (2020). Hubungan Status Sosial Ekonomi Dan Pola Makan Dengan Kejadian Stunting Pada.

Saputri, R. A. (2019). Upaya Pemerintah Daerah Dalam Penanggulangan Stunting Di Provinsi Kepulauan Bangka Belitung. Jdp (Jurnal Dinamika Pemerintahan), 2(2), 152-168. https://doi.org/10.36341/jdp.v2i2.947

Setiawan, E., Machmud, R., \& Masrul, M. (2018). Faktor-Faktor yang Berhubungan dengan Kejadian Stunting pada Anak Usia 24-59 Bulan di Wilayah Kerja Puskesmas Andalas Kecamatan Padang Timur Kota Padang Tahun 2018. Jurnal Kesehatan Andalas, 7(2), 275. https://doi.org/10.25077/jka.v7i2.813

Siringoringo, E. T., Syauqy, A., Panunggal, B., Purwanti, R., \& Widyastuti, N. (2020). Karakteristik Keluarga Dan Tingkat Kecukupan Asupan Zat Gizi Sebagai Faktor Risiko Kejadian Stunting Pada Baduta. Journal of Nutrition College, 9(1), 54-62. https://doi.org/10.14710/jnc.v9i1.26693

Supariasa, I. D. N., \& Purwaningsih, H. (2019). Faktor-Faktor Yang Mempengaruhi Kejadian Stunting Pada Balita Di Kabupaten Malang. Karta Rahardja, 1(2), 55-64. Retrieved from http://ejurnal.malangkab.go.id/index.php/kr

Yadika, A. D. N., Berawi, K. N., \& Nasution, S. H. (2019). Pengaruh Stunting 
terhadap Perkembangan Kognitif dan Prestasi Belajar. Jurnal Majority, 8(2), 273-282.

Yudianti, Y., \& Saeni, R. H. (2016). Pola Asuh Dengan Kejadian Stunting Pada Balita. Jurnal Kesehatan Manarang, 2(1), 21. 